\title{
HEALTH-RELATED QUALITY OF LIFE AND SLEEP QUALITY AMONG COPD PATENTS IN MALAYSIA
}

\author{
Sugunesvaran Parasuraman ${ }^{1}$, Tan Chung Keat ${ }^{2}$ and Nurhayati Binti Mohd Marzuki ${ }^{3}$ \\ ${ }^{1}$ Clinical Research Committee, Hospital Tanjong Karang, Jalan Besar, 45500, Tanjong Karang, Selangor, Malaysia \\ ${ }^{2}$ School of Healthy Aging, Medical Aesthetic and Regenerative Medicine, Faculty of Medicine and Health Sciences, UCSI \\ University, 56000 Cheras, KL, Malaysia \\ ${ }^{3}$ Institut Perubatan Respiratori, Jalan Pahang, Pekeliling, 53000 Kuala Lumpur, Wilayah Persekutuan Kuala Lumpur, \\ Malaysia
}

Corresponding author: Tan Chung Keat

Email: cktan@ucsiuniveristy.edu.my

\begin{abstract}
In Malaysia, chronic respiratory disease including COPD is responsible for $7 \%$ of the total Disability-Adjusted Life Years (DALYs). Sleep disturbance in COPD patients is often underestimated and overlooked clinically. Respiratory symptoms caused by COPD often leads to poor sleep quality and insomnia. Poor sleep quality contributes to frequent episodes of exacerbation which directly increases mortality risk. This study aims to determine health-related quality of life and sleep quality among COPD patients and their associations with severity. In this cross-sectional study, 102 COPD patients classified according to Global Initiative for Chronic Obstructive Lung Disease were evaluated. EQ5D and Pittsburgh Sleep Quality Index (PSQI) questionnaires were used to assess health-related quality of life and sleep quality respectively. Results showed the severity of COPD is significantly associated $(p<0.05)$ with all 5 dimensions of EQ5D among COPD patients in Kuala Lumpur. In this study, 71 patients (69.9\%) were reported to be poor sleepers (PSQl>5) with a mean $\mathrm{global}$ score of $6.93 \pm 4.072$. Sleep quality was also found to be significantly associated ( $p$ $<0.05)$ with COPD severity, in which patients with lower severity showed better sleep quality. In this study, COPD severity was found to be significantly associated with health-related quality of life. As the disease severity progresses, both quality of life and sleep quality worsens gradually. Findings from this study highlight the importance to consider the quality of life and sleep quality as part of the management plan for COPD patients.
\end{abstract}

Keywords: Chronic Obstructive Pulmonary Disease, Health-related Quality of Life, Sleep Quality

\section{INTRODUCTION}

Chronic Obstructive Pulmonary Disease (COPD) is anticipated to be ranked as $3^{\text {rd }}$ in terms of the most common cause of death by the year 2020 after ischemic heart disease and cerebrovascular accident ${ }^{1}$. COPD is also the seventh most common cause of premature deaths in Malaysia in 2010 according to the Global Burden of Disease. Seven percent of Disability-Adjusted Life Years in Malaysia consists of chronic respiratory disease including COPD ${ }^{2}$.

The prevalence of COPD in Malaysia is $4.7 \%$, which is estimated by the COPD prevalence model that utilizes risk factors and epidemiological relationships to project the prevalence rate in a population aged 30 years old and above. COPD patients mostly experience symptoms that significantly affect their quality of life and sleep quality. Common symptoms in COPD patients such as cough, dyspnea, and production of sputum affect the quality of life based on the severity of disease ${ }^{3}$. Health-related quality of life in COPD patients can represent the measure of overall control of the disease. Compromised quality of life is even seen among patients with mild COPD and also keeping in mind that comorbid conditions also affect the relationship between COPD and health- related quality of life $\mathrm{e}^{4}$.

Quality of life in COPD impacts not only the patients themselves, but also on finances. In a study conducted in Sweden, the main indirect cost is the loss of productivity due to disability at which the study also stated $90 \%$ of the indirect costs or annual average costs were SEK 7,079 per person ${ }^{5}$. Sleep disturbance in COPD patients is often underestimated and overlooked clinically. Poor survival in COPD patients is strongly linked to sleep disturbance caused by the disease itself. Respiratory symptoms caused by COPD such as dyspnoea and nocturnal cough leads to poor sleep quality and insomnia ${ }^{6}$. Disturbance in sleep and poor sleep quality contributes to frequent episodes of exacerbation which directly increases mortality risk.

Most COPD patients have trouble initiating sleep, maintaining sleep, reduced REM sleep, microarousals ad frequent sleep stage shifts which disturbs sleep efficiency ${ }^{7}$. Sleep quality and health-related quality of life are the two most important aspects that need to emphasize and explored among COPD patients. This study aims to determine health-related quality of life and sleep quality among COPD patients and to determine 
the association between health-related quality of life and sleep quality among COPD patients.

\section{METHODS}

Declaration of Helsinki was used as ethical guidelines in this study and ethical approval was obtained from Medical Research and Ethics Committee. Patient Information Sheet was given and informed consent form was signed and dated by patient.

\section{Patients' selection.}

The number of patients calculated for this study was 102 , taking into account of 0.05 type 1 error rate, power of, 0.8 and prevalence of COPD at $4.7 \%{ }^{8}$. Patients were recruited using convenient sampling at COPD Specialist Clinic Institut Perubatan Respiratori, Hospital Kuala Lumpur, Malaysia from August 2018 to October 2018. Global Initiative for Chronic Obstructive Lung Disease (GOLD) standard was utilized as criteria to diagnose and stage COPD patients. To group participants according to GOLD Classification 2019, the Refined ABCD Assessment tool was used ${ }^{9}$. The latest FEV1 postbronchodilator performed for each COPD patient was gathered from their respective case files. Inclusion criteria are Malaysians diagnosed with COPD. Exclusion criteria are patients with pulmonary tuberculosis, pregnancy, HIV positive, cancer, and emphysema. The nature and consequences of the study were explained and consent was obtained via an informed consent form from each participant.

\section{Refined ABCD Assessment Tool}

The Refined $A B C D$ assessment tool uses two measures which include the frequency of exacerbations experienced in last year by patient and symptoms of $\mathrm{COPD}^{10}$. Firstly, the number of exacerbations experienced by a COPD patient in the previous 12 months is determined to classify the patient either into high risk of exacerbation or low risk of exacerbation. Secondly, patient's symptoms are assessed using modified Medical Research Council scale (mMRC) to classify the patient into either 'mMRC score 0-1' or 'mMRC score equals or, more than 2'. Based on these two measures, the patient will be categorised into Group A, B, C or D as below:

Group A: Low exacerbation risk, Low symptom severity (nil or one exacerbation in the previous year and $\mathrm{mMRC}$ score 0 - 1 )

Group B: Low exacerbation risk, High symptom severity (nil or one exacerbation in the previous year but $\mathrm{mMRC}$ score equals or more than 2 )

Group C: High exacerbation risk, Low symptom severity (> one or two exacerbations in the previous year and mMRC score $0-1$ )
Group D: High exacerbation risk, High symptom severity ( $>$ one or two exacerbations in the previous year and mMRC score equals or more than 2)

Sleep quality among COPD patients was assessed by using Pittsburgh Sleep Quality Questionnaire (PSQI) ${ }^{11}$. Health-related quality of life was assessed using EQ-5D-3 L questionnaire ${ }^{12}$.

\section{Statistical Analysis}

For categorical variables, $\mathrm{Chi}^{2}$-test was used to compare Sleep Quality and Health-related Quality of Life among COPD patients in GOLD classification, whereas for continuous variables, analysis of variance (ANOVA) was used. Association between sleep quality and HRQoL quantified by Spearman's rank coefficient. Statistics analyzed using SPSS software version 20.0. $P$-values of 0.05 or less are used to show statistical significance.

\section{RESULTS}

Socio-demographic factors of COPD patients The total number of participants in this research from August 2018 until the end of October 2018 is 102 (Table I). The median age of participants is 67.5 (IQR 7) and the mean age of participants is 66.8. In terms of age category, the majority are from the age group of 51- 80 years ago, which accounts for $89.3 \%$ of the total participants in this study. The majority of participants ( $n=96,94.1 \%)$ are male compared to $6 \quad(5.9 \%)$ female participants in this study. In terms of ethnicity, $51(50.0 \%)$ of the participants recruited are Malay and 28 (27.5\%) Chinese and 23 (22.5\%) consist Indian. About $24(23.5 \%)$ are still active smokers. One participant has never smoked before and based on further history, it was clear that the current condition is due to occupational related. Smoking status was found to be statistically significant $(p=0.002)$ among COPD patients in this study. Education levels were mostly secondary school $(n=50,49 \%)$. Regarding monthly incomes, $60(58.8 \%)$ in the category of income ranging from rm1000- 4999.

\section{Health-related Quality of Life (EQ5D-3L)}

Based on this study, there is a significant association between Health-Related Quality of Life and COPD severity $(p<0.01)$. In terms of mobility, 19 participants who have no problem in mobilizing are mostly from GOLD A $(n=13)$, and about 2 of them from GOLD B. Those participants $(n=83)$ who have problems in mobility are from all groups in GOLD classification. GOLD A which is mentioned to be low risk and low symptom burden, contributes about 25 participants (30.1\%) who have problems in mobility. Pain shows a significant association among COPD patients in health-related quality of life. Based on the findings from this study, more participants from GOLD $C$ and $D$ are seen to experience pain comparative GOLD A and GOLD B, which affects 
the quality of life. Anxiety or depression among COPD patients shows significant association $(p<0.05)$ with GOLD classification. Participants from GOLD D shows the highest percentage of COPD patients who have some degree of anxiety or depression. The 5 dimensions of EQ5D are summarized in general, regardless of COPD severity in the table below (Table II).

EQVAS portrays participants' health state at which 100 on the scale indicates health state at its best and 0 on the scale is health state at its worst. About 30 participants from GOLD D showed EQVAS 26 - 50, whereas 28 participants from GOLD A showed EQVAS 51 - 75 and 8 participants from GOLD A showed EQVAS 76 - 100. Based on this finding, participants $(n=36,94.7 \%)$ from the less severe COPD group (GOLD A) chose a better health state on the scale provided whereas, the majority of participants $(n=30,93.8 \%)$ from the most severe form of COPD group (GOLD D) chose worse health state on the scale.

\section{Sleep Quality}

COPD severity was found to be significantly associated $(P<0.05)$ with all the PSQI parameters, which includes subjective sleep quality, sleep duration, sleep latency, daytime dysfunction, step disturbances, habitual sleep efficiency, and use of sleep medications (Table III). Participants from GOLD class A which is less severe show a higher tendency of better sleeping quality, with 25 patients reported to have good sleep, which scored less than 5 on the Global Score of PSQI (Table IV). The majority of participants from GOLD D which most severe in COPD severity found to be poor sleepers, with 32 reported to have poor sleep (scored 5 or more on Global Score of PSQI).

Table 1: Socio-demographic characteristics of the respondents (COPD patients)

\begin{tabular}{|c|c|c|c|c|c|c|c|}
\hline Characteristic & & Median & $\bar{A}$ & $\mathrm{~B}$ & $\mathrm{C}$ & $\mathrm{D}$ & p value \\
\hline Age (Median, IQR) & & 67.5 & & - & & & - \\
\hline \multirow[t]{6}{*}{ Age Group } & $30-40$ & & $1(50.0 \%)$ & $0(0.0 \%)$ & $1(50.0 \%)$ & $0(0.0 \%)$ & \\
\hline & $41-50$ & & $0(0.0 \%)$ & $0(0.0 \%)$ & $3(75.0 \%)$ & $1(25.0 \%)$ & \\
\hline & $51-60$ & & $3(14.3 \%)$ & $2(9.5 \%)$ & $9(42.9 \%)$ & $7(33.3 \%)$ & \\
\hline & $61-70$ & & $16(50.0 \%)$ & $0(0.0 \%)$ & $7(21.9 \%)$ & $9(28.1 \%)$ & \\
\hline & $71-80$ & & $14(36.8 \%)$ & $3(7.9 \%)$ & $6(15.8 \%)$ & $15(39.5 \%)$ & \\
\hline & $>80$ & & $4(80.0 \%)$ & $1(20.0 \%)$ & $0(0.0 \%)$ & $0(0.0 \%)$ & \\
\hline \multirow[t]{4}{*}{ Ethnicity } & Malay & & $14(27.5 \%)$ & $4(7.8 \%)$ & $17(33.3 \%)$ & $16(31.4 \%)$ & $p=0.039^{*}$ \\
\hline & Indian & & $12(52.2 \%)$ & $2(8.7 \%)$ & $5(21.7 \%)$ & $4(14.7 \%)$ & \\
\hline & Chinese & & $12(42.9 \%)$ & $0(0.0 \%)$ & $4(14.3 \%)$ & $12(42.9 \%)$ & \\
\hline & & & & & & & $p=0.103$ \\
\hline \multirow[t]{3}{*}{ Gender } & Male & & $35(36.5 \%)$ & $5(5.2 \%)$ & $26(27.1 \%)$ & $30(31.2 \%)$ & \\
\hline & Female & & $3(50.0 \%)$ & $1(16.7 \%)$ & $0(0.0 \%)$ & $2(33.3 \%)$ & \\
\hline & & & & & & & $\mathrm{p}=0.366$ \\
\hline \multirow[t]{4}{*}{ Smoking status } & Active Smoker & & $6(25.0 \%)$ & $0(0.0 \%)$ & $9(37.5 \%)$ & $9(37.5 \%)$ & \\
\hline & Ex-smoker & & $32(41.6 \%)$ & $5(6.5 \%)$ & $17(22.1 \%)$ & $23(29.9 \%)$ & \\
\hline & Never smoked before & & $0(0.0 \%)$ & $1(100 \%)$ & $0(0.0 \%)$ & $0(0.0 \%)$ & \\
\hline & & & & & & & $\mathrm{p}=0.002^{*}$ \\
\hline \multirow[t]{5}{*}{ Education level } & Primary school & & $7(25.0 \%)$ & $3(10.7 \%)$ & $7(25.0 \%)$ & $11(39.3 \%)$ & \\
\hline & Secondary school & & $20(40.0 \%)$ & $3(6.0 \%)$ & $11(22.0 \%)$ & $16(32.0 \%)$ & \\
\hline & Diploma & & $8(44.4 \%)$ & $0(0.0 \%)$ & $5(27.8 \%)$ & $5(27.8 \%)$ & \\
\hline & Bachelor & & $3(50.0 \%)$ & $0(0.0 \%)$ & $3(50.0 \%)$ & $0(0.0 \%)$ & \\
\hline & & & & & & & $\mathrm{p}=0.487$ \\
\hline \multirow[t]{4}{*}{ Monthly income } & $<\mathrm{rm} 1000$ & & $15(36.6 \%)$ & $3(7.3 \%)$ & $10(24.4 \%)$ & $13(31.7 \%)$ & \\
\hline & rm1000-rm4999 & & $22(36.7 \%)$ & $3(5.0 \%)$ & $16(26.7 \%)$ & $19(31.7 \%)$ & \\
\hline & rm5000-rm10000 & & $1(100 \%)$ & $0(0.0 \%)$ & $0(0.0 \%)$ & $0(0.0 \%)$ & \\
\hline & & & & & & & $\mathrm{p}=0.922$ \\
\hline
\end{tabular}


Table 2: EQ5D-3L dimension based on COPD GOLD Classification

\begin{tabular}{|c|c|c|c|c|c|c|}
\hline \multirow{3}{*}{ EQ-D5 } & \multicolumn{6}{|c|}{ GOLD Classification } \\
\hline & & & & & & \\
\hline & & $A$ & B & C & D & Total \\
\hline MOBILITYa & No problem & 13 & 2 & 4 & 0 & 19 \\
\hline$p$ value 0.002 & Problems & 25 & 4 & 22 & 32 & 83 \\
\hline SELFCARE ${ }^{\mathrm{a}}$ & No problem & 34 & 4 & 22 & 7 & 67 \\
\hline$p$ value 0.000 & Problems & 4 & 2 & 4 & 25 & 32 \\
\hline USUAL ACTIVITYa & No problem & 30 & 1 & 19 & 3 & 53 \\
\hline $\mathrm{p}$ value 0.000 & Problems & 8 & 5 & 7 & 29 & 40 \\
\hline PAIN ${ }^{a}$ & No problem & 37 & 4 & 22 & 19 & 82 \\
\hline$p$ value 0.001 & Problems & 1 & 2 & 4 & 13 & 20 \\
\hline ANXIETYa & No problem & 36 & 4 & 23 & 14 & 77 \\
\hline$p$ value 0.000 & Problems & 2 & 2 & 3 & 1 & 25 \\
\hline
\end{tabular}

${ }^{a}$ Analysis using Pearson Chi-square test $(p<0.05)$

Table 3: PSQI in association with GOLD classification

GOLD Classification

\begin{tabular}{lccccc}
\hline \multicolumn{1}{c}{ PITTSBURGH SLEEP QUALITY INDEX } & & & \multicolumn{2}{c}{ Total } \\
& A & B & C & D & \\
POOR SLEEPERS & 13 & 5 & 21 & 32 & 71 \\
GOOD SLEEPERS & 25 & 1 & 5 & 0 & 31 \\
Total & 38 & 6 & 26 & 32 & 102 \\
\hline
\end{tabular}

${ }^{a}$ Analysis using Pearson Chi-square test $(p<0.05)$

Association between Health-related Quality of Life and Sleep Quality among COPD patients This study showed that the association between EQ5D and PSQI was significant (Table V). Sleep quality was significantly associated $(P<0.05)$ with mobility among patients, where most of the patients who had problems in mobility $(79.5 \%)$ are poor sleepers. Sleep quality was also reported to be significantly associated $(P<0.05)$ with self-care among patients. A percentage of $97.1 \% \quad(n=34)$ participants who had problems in self-care are poor sleepers. On the other hand, 91.8\% n=45 participants who had problems in their usual activities, such as work, family, or leisure activities were found to be poor sleepers. About 95.0\% of participants who reported some degree of pain or discomfort are poor sleepers, this showed sleep quality was significantly associated ( $p<$ 0.05) with pain or discomfort among COPD patients. Besides that, $96.0 \%$ of participants who showed some degree of anxiety were poor sleepers. Sleep quality was significantly associated ( $\mathrm{p}$-value $<0.05$ ) with anxiety or depression among COPD patients. In a nutshell, health-related quality of life (EQ5D) and sleep quality (PSQI) among COPD patients showed significant association with each other $(\mathrm{P}<0.05)$.

Correlation of Health-related Quality of Life with Disease severity and sleep quality

Apart from the above analysis, the correlation of Health-related Quality of Life (EQ5D) with GOLD classification and Sleep Quality (PSQI) was analyzed using Spearman's correlation (Table VI). In this analysis, EQ5D self-care domain was reported having a moderate positive correlation with GOLD $\left(r^{2}=0.561\right)$ and PSQI $\left(r^{2}=0.618\right)$ which were statistically significant $(p<0.05)$. Similar findings were reported with the EQ5D usual activities domain at which it showed a moderate positive correlation with GOLD $\left(r^{2}=0.568\right)$ and PSQI $\left(r^{2}=0.582\right)$. Apart from that, findings showed a weak positive correlation between the EQ5D pain domain with GOLD $\left(r^{2}=0.385\right)$ and PSQI $\left(r^{2}=\right.$ $0.377)$, which was statistically significant $(P<0.05)$.

EQ5D anxiety domain showed weak positive with GOLD $\left(r^{2}=0.46\right)$ and moderate positive correlation with PSQI $\left(r^{2}=0.538\right)$. Other EQ5D domains (mobility and pain) were reported having a weak correlation with GOLD and PSQI, at which $r^{2}$ strength of correlation range from 0.335 to 0.46 
Table 4: Association of PSQI scores with COPD severity

\section{Gold Classification}

\begin{tabular}{lcccccc}
\hline \multirow{2}{*}{ PSQI SCORES } & & & & & \\
Subjective Sleep Quality & 0 & $14(77.8 \%)$ & $0(0.0 \%)$ & $4(22.2 \%)$ & $0(0.0 \%)$ & $\mathrm{p}=0.000^{*}$ \\
& 1 & $23(44 . @ \%)$ & $4(7.7 \%)$ & $19(36.5 \%)$ & $6(11.5 \%)$ & \\
Sleep Duration & 2 & $1(3.6 \%)$ & $2(7.1 \%)$ & $3(10.7 \%)$ & $22(78.6 \%)$ & \\
& 3 & $0(0.0 \%)$ & $0(0.0 \%)$ & $0(0.0 \%)$ & $4(100.0 \%)$ & \\
Sleep Latency & 0 & $22(48.9 \%)$ & $2(4.4 \%)$ & $14(31.1 \%)$ & $7(15.6 \%)$ & $\mathrm{p}=0.001^{*}$ \\
& 1 & $10(45.5 \%)$ & $3(13.6 \%)$ & $5(22.7 \%)$ & $4(18.2 \%)$ & \\
& 2 & $6(26.1 \%)$ & $1(4.3 \%)$ & $5(21 \ldots .7 \%)$ & $11(47.8 \%)$ & \\
Daytime Dysfunction & 3 & $0(0.0 \%)$ & $0(0.0 \%)$ & $2(16.7 \%)$ & $10(83.3 \%)$ & \\
& 0 & $18(69.2 \%)$ & $0(0.0 \%)$ & $6(23.1 \%)$ & $2(7.7 \%)$ & $\mathrm{p}=0.000^{*}$ \\
& 1 & $14(42.8 \%)$ & $2(6.3 \%)$ & $12(37.5 \%)$ & $4(12.5 \%)$ & \\
Step Disturbance & 2 & $5(29.4 \%)$ & $3(17.6 \%)$ & $4(23.5 \%)$ & $5(29.4 \%)$ & \\
& 3 & $1(3.7 \%)$ & $1(3.7 \%)$ & $4(14.8 \%)$ & $21(77.8 \%)$ & \\
& 0 & $18(56.3 \%)$ & $1(3.1 \%)$ & $10(31.3 \% 0$ & $3(9.4 \%)$ & $\mathrm{p}=0.000^{*}$ \\
& 1 & $18(41.9 \%)$ & $3(7.0 \%)$ & $15(34.9 \%)$ & $7(16.3 \%)$ & \\
Habitual Sleep Efficiency & 2 & $2(7.4 \%)$ & $2(7.4 \%)$ & $1(3.7 \%)$ & $22(81.5 \%)$ & \\
& 3 & $0(0.0 \%)$ & $0(0.0 \%)$ & $0(0.0 \%)$ & $0(0.0 \%)$ & \\
& 0 & $0(0.0 \%)$ & $0(0.0 \%)$ & $2(100.0 \%)$ & $0(0.0 \%)$ & $\mathrm{p}=0.009^{*}$ \\
& 1 & $34(43.0 \%)$ & $5(6.3 \%)$ & $21(26.6 \%)$ & $19(24.1 \%)$ & \\
& 2 & $4(19.0 \%)$ & $1(4.8 \%)$ & $3(14.3 \%)$ & $13(61.9 \%)$ & \\
& 3 & $0(0.0 \%)$ & $0(0.0 \%)$ & $0(0.0 \%)$ & $0(0.0 \%)$ & \\
& 0 & $35(87.5 \%)$ & $4(10.0 \%)$ & $1(2.5 \%)$ & $0(0.0 \%)$ & $\mathrm{p}=0.000^{*}$ \\
& 1 & $3(11.1 \%)$ & $2(7.4 \%)$ & $17(63.0 \%)$ & $5(18.5 \%)$ & \\
& 2 & $0(0.0 \%)$ & $0(0.0 \%)$ & $7(26.9 \%)$ & $19(73.1 \%)$ & \\
& 3 & $0(0.0 \%)$ & $0(0.0 \%)$ & $1(11.1 \%)$ & $8(88.9 \%)$ & \\
& 0 & $37(39.8 \%)$ & $5(5.4 \%)$ & $25(26.9 \%)$ & $26(28.0 \%)$ & $\mathrm{p}=0.004^{*}$ \\
& 1 & $1(14.3 \%)$ & $0(0.0 \%)$ & $1(14.3 \%)$ & $5(71.4 \%)$ & \\
& 2 & $0(0.0 \%)$ & $0(0.0 \%)$ & $0(0.0 \%)$ & $1(100.0 \%)$ & \\
& 3 & $0(0.0 \%)$ & $1(100.0 \%)$ & $0(0.0 \%)$ & $0(0.0 \%)$ & \\
& & & & & &
\end{tabular}

Table 5: Summary of Association between EQ5D and PSQI

\begin{tabular}{llcccc}
\hline \multicolumn{1}{c}{ EO5D DIMENSION } & & & & \\
\hline \multirow{3}{*}{ MOBILITY } & & POOR SEELPERS & GOOD SLEEPERS & Total & p value \\
& No problem & $8(42.1 \%)$ & $11(57.9 \%)$ & 19 & $0.006^{*}$ \\
SELFCARE & Problems & $63(75.9 \%)$ & $20(24.1 \%)$ & 83 & \\
& No problem & $37(55.2 \%)$ & $30(44.8 \%)$ & 67 & $0.000^{*}$ \\
USUAL ACTIVITIES & Problems & $34(97.1 \%)$ & $1(2.9 \%)$ & 35 & \\
& No problem & $26(49.1 \%)$ & $27(50.9 \%)$ & 53 & $0.000^{*}$ \\
PAIN/DISCOMFORT & Problems & $45(91.8 \%)$ & $4(8.2 \%)$ & 49 & \\
\multirow{2}{*}{ ANXIETY } & No problem & $52(63.4 \%)$ & $30(36.6 \%)$ & 82 & $0.006^{*}$ \\
& Problems & $19(95.0 \%)$ & $1(5.0 \%)$ & 20 & \\
& No problem & $47(61.0 \%)$ & $30(39.0 \%)$ & 77 & $0.001^{*}$ \\
& Problems & $24(96.0 \%)$ & $14.0 \%)$ & 25 & \\
\hline
\end{tabular}


Table 6: Correlation of EQ5D with GOLD classification and PSQI

\begin{tabular}{lcccc}
\hline EQ5D $^{\mathrm{b}}$ & $\begin{array}{c}\text { GOLD } \\
\mathrm{r}^{2}\end{array}$ & $p$ value & $\begin{array}{c}\text { PSQI } \\
\mathrm{r}^{2}\end{array}$ & $p$ value \\
\hline & & & & \\
Mobility & 0.385 & 0.002 & 0.337 & 0.006 \\
Selfcare & 0.561 & 0.000 & 0.618 & 0.000 \\
Usual activity & 0.568 & 0.000 & 0.582 & 0.000 \\
Pain & 0.377 & 0.001 & 0.335 & 0.006 \\
Anxiety & 0.46 & 0.000 & 0.538 & 0.001 \\
\hline
\end{tabular}

${ }^{b}$ Analysis using Spearman's correlation.

\section{DISCUSSION}

Socio-demographic profile of COPD patients The median age of participants in this study was $67.5 \quad(7 \mathrm{IQR})$ with males being the predominant gender. The most common age group in the study reported to be COPD patients are those from $51-80$ years of age and the majority of them were males. In a study conducted in Taiwan, elderly patients were the most common, and the male gender was $98 \%{ }^{13}$. It is perceived that patients usually present after the development of chronic disease progression which explains the predominantly older age group among COPD patients ${ }^{14}$. This is probably may be due to a lack of awareness among patients regarding recognition of early symptoms of COPD. Approximately similar findings were seen in a study in which the majority of the participants in that study were males 127 (90.7\%) and most $87(62.14 \%)$ of them were between the age group of 61-86 years ${ }^{15}$. Besides that, also reported that the Malays (55.9\%) were highest in terms of the prevalence of smoking, and the age category of 21-30 years (59.3\%) reported highest in the prevalence of smoking ${ }^{16}$. In this study, $75.5 \%$ of the participants were ex-smokers and $23.5 \%$ were active smokers, implies the majority of smokers and ex-smokers are associated with COPD, which was statistically significant $(p=0.002)$.

Health-related Quality of Life in COPD patients COPD severity is significantly associated $(p<0.05)$ with all 5 dimensions of EQ5D which includes mobility, self-care, usual activities, pain or discomfort, and anxiety among COPD patients. The progression of the disease causes functional ability deterioration which may lead to emotional issues such as anxiety. This can be seen in this study in which most activities involving functional ability such as mobility, self-care, and usual activities are reported to have the majority number of participants from GOLD C and GOLD D (the severe form of COPD severity). In a study conducted in Italy, the frequency of symptoms increased significantly with the severity of COPD ${ }^{17}$. Besides functional abilities, emotional issues such as anxiety or depression also reported being increasing in number as disease severity worsening from GOLD A to GOLD D. Probably COPD patients may face or experience emotional changes such as anxiety as they realize their functional abilities worsen as the disease progresses ${ }^{6}$. In this study also, pain or discomfort in EQ5D reported to increase as disease severity progression from GOLD A to GOLD D. Pain or discomfort in COPD patients can be due to pathophysiological changes that happen when COPD disease progresses and also can due to worsening functional abilities. In a study conducted at West Park Healthcare Centre, it was found that in the severe to very severe COPD group, the presence of pain was noticed among stable participants ${ }^{18}$. According to another study, with increasing severity of the disease, healthrelated quality of life in COPD patients deteriorates and also stated that this deterioration is linearly related with predicted values of Forced Expiratory Volume of $1 \mathrm{sec}$ $\left(\mathrm{FEV}_{1}\right)^{19}$. In another study, both EQ-5D utility score and EQ-5D Visual Analogue Scale declined significantly between moderate and severe COPD ${ }^{20}$. A cross-sectional analysis conducted in German reported a worsening mean score of SGRQ, CAT, and EQ5D with higher COPD grades ${ }^{21}$.

\section{Sleep Quality among COPD patients}

Many studies reported nighttime symptoms and poor sleep quality are seen more often among COPD patients. Poor sleep quality among COPD patients is also majorly contributed by factors such as obstructive sleep apnoea, psychiatric disorder and medication-related insomnia ${ }^{22}$. In this study, participants $(n=71,70.0 \%)$ had mean PSQI scores of $6.93 \pm 4.072$. Similar reports were also noted in studies conducted in Israel, Iran and Taiwan with theme scores of $11.0 \pm 5.4,8.03 \pm 3.66$ and $9.41 \pm 4.33$ respectively ${ }^{23-25}$. In this study, findings suggestive of worsening sleep quality as COPD disease severity progresses. Similar findings are seen in a study conducted by Lewis and co-workers (2008) which states $61 \%$ had poor quality sleep (PSQI>5) are from moderate to severe COPD group which had 59 patients ${ }^{26}$. Many studies showed that 
poor sleep quality causes many negative effects to individuals such as being fatigue, anxiety or changes in cognitive functions ${ }^{27,28}$.

\section{Health-related Quality of Life and Sleep Quality among COPD patients}

From this study, the association of all 5 dimensions of EQ5D (Mobility, Self-care, Usual Activities, Pain or Discomfort, Anxiety) with sleep quality (which categorized based Global Score of PSQl) was found to be statistically significant $(p<0.05)$. Most participants $(n=66,75.9 \%)$ who had problems in mobility were poor sleepers. About $97.1 \%$ of participants who had problems in self-care are poor sleepers. Parallel findings noted in the study assessed self-disturbance and implication of selfcare in failure which showed disturbed sleep is associated with symptoms and functional deficits ${ }^{29}$. Usual activities were found to be significantly $(P<0.05)$ associated with sleep quality, where $91.8 \%$ of participants who had problems in their usual activities are poor sleepers. About 95.0\% of participants who reported some degree of pain or discomfort are poor sleepers. Pain among COPD patients varies. In a cross-sectional study carried out with data collected from the European Health Interview Surveys for Spain (EHSS) conducted in years 2009/2010, the prevalence of chronic neck pain, chronic lower back pain, and migraine were significantly higher among COPD patients in comparison with controls ${ }^{30}$. Many factors, including pain, disease process, and medication used to control the disease may disturb sleep. The natural course of painful disease can be adversely affected by sleep disturbance. This vicious circle can be controlled among a group of patients who suffer from the painful disorder in term of improving sleep quantity and quality ${ }^{31}$. Besides that, $96.0 \%$ of participants who showed some degree of anxiety are poor sleepers $(p<0.05)$. Impaired health positively associated with anxiety. In a prospective study, the scores of SGRQ for patients with acute exacerbation of COPD admitted in 5 university hospitals in the Nordic countries, were up to 12 units after COPD discharged from hospital. This is considered 3 times clinically significant ${ }^{32}$.

\section{Correlation of Health-related Quality of Life with disease severity and sleep quality.}

Health-related Quality of Life (EQ5D) was significantly associated with GOLD and PSQI $(p<0.05)$. By analysis using Spearman's correlation, each domain of EQ5D was reported to have a positive correlation with disease severity (GOLD) and sleep quality (PSQI). Varied strength of correlations seen upon analyzing each domain of EQ5D. Both self-care domain and usual activities domain of EQ5D showed a moderate positive correlation with disease GOLD and PSQI. These findings probably due to the nature and progress of COPD condition, disease progression affects the ability to do usual activities and selfcare routine such studying, housework, spending leisure time with family, dressing and cleaning own self. Similar finding noted in another study, quality of life is compromised quality of life seen in COPD which worsens as the disease progresses ${ }^{8}$. Nonetheless, due to smaller sample size in this study, all the correlations being establish were of weak or moderate strength. Future study with bigger sample should be able to establish a stronger correlation relationship.

\section{CONCLUSION}

This study identified that COPD patients have their quality of life and sleep quality significant association with disease severity. Sleep quality and health-related quality of life worsen gradually as the disease severity progresses. Sleep quality of an individual who suffers from COPD also affects health-related quality of life. Findings from this study may assist to manage COPD patient more accurately since we know that pharmacological treatment is not comprehensive enough to manage COPD patients. Quality of life and sleep quality should be considered when it comes to the management plan for COPD patients.

\section{Conflict of interest}

The authors declare no potential conflict of interest.

\section{Acknowledgement}

I would also like to show our gratitude to Ministry of Health Malaysia for allowing me to take my samples from Institut Perubatan Respiratori, Kuala Lumpur.

\section{Funding}

This work was supported by Ministry of Education, under the funding of Fundamental Research Grant Scheme [FRGS/2/2014/SKK10/UCSI/03/1].

\section{REFERENCES}

1. Onishi K. Total management of chronic obstructive pulmonary disease (COPD) as an independent risk factor for cardiovascular disease. J Cardiol 2017; 70(2):128-34.

2. Guidelines in The Management of Chronic Obstructive Pulmonary Disease-A Consensus Statement of The Ministry of Health of Malaysia, Academy of Medicine of Malaysia And Malaysian Thoracic Society. Med J Malaysia 1999; 54:387-400.

3. Oliveira AS, Munhá J, Bugalho A, et al. Identification and assessment of COPD exacerbations. Pulmonology 2018; 24(1):42-7.

4. Ferrer $M$, Alonso J, Morera, J, et al. Chronic obstructive pulmonary disease stage and health-related quality of life. Ann Intern Med 127, 1072-1079. 
5. Jansson SA, Andersson F, Borg S, et al. Costs of COPD in Sweden according to disease severity. Chest 2002; 122(6):19942002.

6. Omachi TA, Blanc PD, Claman DM, et al. Disturbed sleep among COPD patients is longitudinally associated with mortality and adverse COPD outcomes. Sleep Med 2012; 13(5):476-83.

7. McNicholas WT, Verbraecken J, Marin JM. Sleep disorders in COPD: the forgotten dimension. Eur Respir Rev 2013; 22(129):365-75.

8. Dignani, L., Toccaceli, A., Lucertini, C., et al Sleep and quality of life in people with COPD: a descriptive-correlational study. Clinical nursing research, 25(4), pp.432-447

9. Global Initiative for Chronic Obstructive Lung Disease. [May;2019];https://goldcopd.org/wpcont ent/uploads/2016/12/wms-GOLD-2017Pocket-Guide.pdf

10. Vogelmeier CF, Criner GJ, Martinez FJ, et al. Global strategy for the diagnosis, management, and prevention of chronic obstructive lung disease 2017 report. GOLD executive summary. Am J Respir Crit Care Med 2017; 195(5):557-82.

11. Buysse DJ, Reynolds III CF, Monk TH, et al. The Pittsburgh Sleep Quality Index: a new instrument for psychiatric practice and research. Psychiatry Res 1989; 28(2):193213

12. Rabin R, Charro FD. EQ-SD: a measure of health status from the EuroQol Group. Ann Med 2001; 33(5):337-43

13. Chang $\mathrm{CH}$, Chuang LP, Lin SW, et al. Factors responsible for poor sleep quality in patients with chronic obstructive pulmonary disease. BMC Pulm Med 2016; 16(1):118.

14. Balcells E, Gea J, Ferrer J, et al. Factors affecting the relationship between psychological status and quality of life in COPD

Health Qual Life Outcomes 2010; $8(1): 108$.

15. Castelino F, Prabhu M, Pai MS, et al. Socio-demographic and clinical characteristics of Chronic Obstructive Pulmonary Disease (COPD) patients. Manipal Journal of Nursing and Health Sciences (MJNHS). 2017; 3(2):55-8.
16. Lim HK, Ghazali SM, Kee CC, et al. Epidemiology of smoking among Malaysian adult males: prevalence and associated factors. BMC Public Health 2013; 13(1):8.

17. Nicola S, Raffaele Al, Francesco B, et al. Circadian rhythm of COPD symptoms in clinically based phenotypes. BMC Pulm Med $2019 ; 19(1): 171$.

18. Lee AL, Goldstein RS, Brooks D. Chronic pain in people with chronic obstructive pulmonary disease: prevalence, clinical and psychological implications. Chronic Obstr Pulm Dis 2017;4(3):194.

19. Ståhl $E$, Lindberg $A$, Jansson $S A$, et al. Health-related quality of life is related to COPD disease severity. Health Qual Life Outcomes 2005; 3(1):56.

20. Hong JY, Kim SY, Chung KS, et al. Factors associated with the quality of life of Korean COPD patients as measured by the EQ-5D. Qual Life Res 2015; 24(10):254958.

21. Wacker ME, Jörres RA, Karch A, et al. Assessing health-related quality of life in COPD: comparing generic and diseasespecific instruments with focus on comorbidities. BMC Pulm Med 2016; 16(1):70.

22. McNicholas WT, Calverley PM, Lee A, et al. Long-acting inhaled anticholinergic therapy improves sleeping oxygen saturation in COPD. Eur Respir J 2004; 23(6):825-31.

23. Zohal MA, Yazdi Z, Kazemifar AM. Daytime sleepiness and quality of sleep in patients with COPD compared to control group. Glob J Health Sci 2013; 5(3):150.

24. Scharf SM, Maimon N, Simon-Tuval T, et al. Sleep quality predicts quality of life in chronic obstructive pulmonary disease. Int J Chron Obstruct Pulmon Dis 2011; $6: 1$

25. Lan CC, Huang $\mathrm{HC}$, Yang $M C$, et al. Pulmonary rehabilitation improves subjective sleep quality in COPD. Respiratory care 2014; 59(10):1569-76.

26. Lewis CA, Ferguson W, Eaton $\mathrm{T}$, et al. Isolated nocturnal desaturation in COPD: prevalence and impact on quality of life and sleep. Thorax 64:133-138

27. Hynninen MJ, Pallesen S, Nordhus IH. Factors affecting health status in COPD patients with co-morbid anxiety or 
depression. Int J Chron Obstruct Pulmon Dis 2007 ;2(3):323.

28. Shackell BS, Jones RCM, Harding G, et al. Am I going to see the next morning? A qualitative study of patients' perpectives of sleep in COPD. Prim Care Respir J 2007;16(6) 378-383.

29. Redeker NS. Sleep disturbance in people with heart failure: implications for selfcare.

J Cardiovasc Nurs 2008; 23(3):231-8.

30. de Miguel-Díez J, López-de-Andrés A, Hernandez-Barrera V, et al. Prevalence of
Pain in COPD Patients and Associated Factors. Clin J Pain 2018; 34(9):787-94.

31. Onen SH, Onen F, Courpron P, et al. How pain and analgesics disturb sleep. Clin J Pain 2005; 21(5):422-31.

32. Gudmundsson G, Gislason T, Janson C, et al. Depression, anxiety and health status after hospitalization for COPD: a multicentre study in the Nordic countries. Respir Med 2006; 100(1):87-93. 